\title{
A STUDY OF BEHAVIOURAL DISORDERS IN CHILDREN WITH EPILEPSY
}

\author{
Shilpa Telgote 1
}

1Associate Professor, Department of Psychiatry, GMC, Akola.

ABSTRACT
BACKGROUND
Like many other chronic diseases, the clinical picture and course of epilepsy is also influenced by psychiatric and social problems
with it and especially so in children. Surveys have shown that the proportion of behavioural problems is more in children with
epilepsy than in those with other chronic physical illnesses and children in general population.
This study is an attempt to assess the spectrum of behavioural disorders in school going epileptic children.

\section{MATERIALS AND METHODS}

A total of 30 patients with epilepsy were included in this study. The most common type of seizures seen in this study sample was generalised tonic-clonic epilepsy. This was followed by complex partial seizures and simple partial seizures with secondary generalisation.

\section{RESULTS}

Highest rate of total behavioural problems was found in epileptic children as compared to those of healthy controls. Amongst the behavioural problems, statistically significant difference was found for aggression, attention and somatic problem.

\section{CONCLUSION}

The children with epilepsy are at increased risk of behavioural problems. They should be closely monitored for development of behavioural problem and a regular referral for psychiatric evaluation must be made.

\section{KEYWORDS}

Epilepsy, Children, Behavioural Disorders.

HOW TO CITE THIS ARTICLE: Telgote S. A study of behavioural disorders in children with epilepsy. J. Evolution Med. Dent. Sci. 2018;7(01):1-4, DOI: $10.14260 /$ jemds/2018/1

\section{BACKGROUND}

Epilepsy in its truest sense is a neuropsychiatric phenomenon. The epileptic seizure is a name for occasional, sudden, excessive, rapid and local discharges of grey matter. Epilepsy is said to occur when seizures occur repeatedly due to underlying neurological process.

The developing brain of child is uniquely susceptible to epilepsy making it one of the most prevalent form of chronic and disabling childhood disease. Like many other chronic diseases, the clinical picture and course of epilepsy is also influenced by psychiatric and social problems with it and especially so in children. Life with epilepsy generally involves more than adjustment to intermittent loss of control, longterm drug therapy and medical surveillance. People with epilepsy also have to learn to cope with degree of public antipathy towards their conditions.

Many of those who have written on psychological problems associated with epilepsy have confidently asserted that these are almost always caused by public discrimination arising out of the perception of epilepsy as stigmatising. ${ }^{1}$ Nevertheless seizure is a frightening event especially for a child's family causing parental worry regarding recurrence and effect of seizure on child's mental capabilities.

'Financial or Other Competing Interest': None.

Submission 16-11-2017, Peer Review 12-12-2017,

Acceptance 19-12-2017, Published 01-01-2018.

Corresponding Author:

Dr. Shilpa Telgote,

Flat No. 101, Mangalmurti Apts.

Malkapur Road,

Akola.

E-mail: drshilpapatelgotes@gmail.com

DOI: $10.14260 / \mathrm{jemds} / 2018 / 1$

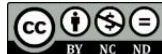

Surveys have shown that proportionately more of them have cognitive and behavioural problems than children with other chronic physical illnesses ${ }^{2}$ and children in general population. Thus, epileptic children can be considered as a high-risk group for development of such problems.

The cause of psychiatric impairment in epileptic children is multifactorial probably involving a combination of effect of seizure, effect of antiepileptic medication, poor child and family adaptation to seizures and neurological dysfunction leading to both seizures and behavioural problems. ${ }^{3,4}$

Keeping these facts in mind, this is an attempt to study the spectrum of behavioural disorders in school going epileptic children.

\section{Aims and Objectives}

1. To assess the spectrum of behavioural problems in epileptic children as compared to those of controls.

2. To study the correlation between characteristics of epilepsy and behavioural patterns in epileptic children.

\section{MATERIALS AND METHODS}

The patients were selected from Outpatient Department of Paediatrics of a tertiary care hospital.

\section{Sample Size}

30.

\section{Sample Selection}

Consecutive patients were assessed.

\section{Inclusion Criteria}

1. Age- 5-15 years.

2. Both sexes. 
3. Diagnosed case of epilepsy more than 6 months of duration.

4. Presently on prescribed anti-epileptic drugs.

\section{Exclusion Criteria}

1. IQ less than 70.

2. Any other neurological illness.

3. Any other chronic physical illness.

\section{Instruments Used}

1. Semi-structured proforma.

2. Child behaviour checklist.

The behavioural functioning of child will be assessed by the parents rating of the CBCL. The CBCL consists of 118 items on which parents rate their children using a 3-point scale with higher scores reflecting more problems. Past research has shown the scales to have strong reliability and validity. It has been used in study of epileptic children. [Ott D, Siddarth P, Gurbani S, Koh S, Tourndy A, Shields W.D, Caplan R. Behavioral disorders in Paed. Epilepsy: under psy. Med. Epilepsia. 2003 Apr;44[4]:591-7.] [Johhn K Austin, Michael W. Ristinger, and Laurel A Beckett. Correlates of behaviour problems in children with epilepsy: Epilepsia 1992;33[6]:1115-1122.

\section{The CBCL Provides}

- Total behaviour problem score and,

- Second order factor scores.

- Internalising problems.

- Externalising problems and

- 8 syndrome scores.

- Withdrawn.

- Somatic.

- Anxiety \& depression.

- Social problems.

- Thought problems.

- Attention problems.

- Delinquency.

- Aggression.

International League against Epilepsy Commission on Classification $^{5}$

1. Partial Seizures (Consciousness Retained)
[Focal/Local]
A. Simple Partial
1. Motor.
2. Sensory.
3. Autonomic.
4. Psychic.

\section{B. Complex Partial (Consciousness Impaired)}

1. Simple partial followed by impaired consciousness.

2. With impairment consciousness at onset.

\section{Partial Seizures with Secondary Generalization.}

\section{Generalised Seizures}

A. Absences

1. Typical
B. Myoclonic
C. Clonic
D. Tonic
E. Generalised tonic-clonic.

\section{Unclassified Epileptic Seizures}

\section{Method}

Study design was a cross-sectional, comparative study. Sample size of 30 was selected. Considering proportion of behavioural problems in epileptics as $50 \%$.

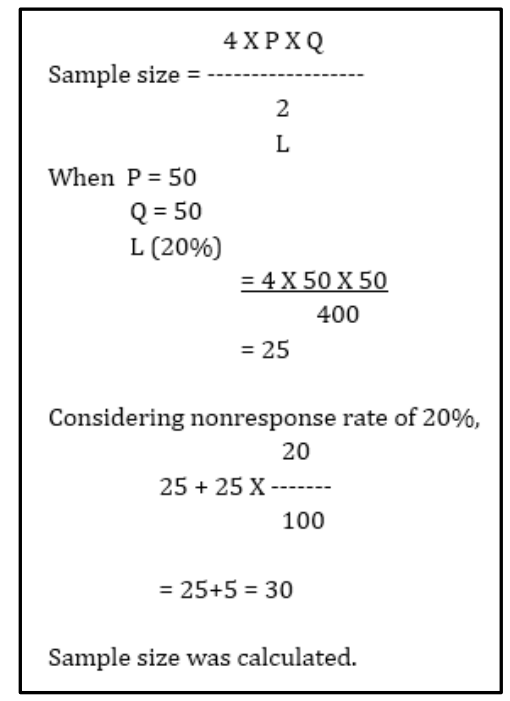

Children between age group of 5 to 15 years were selected from paediatric OPD of the tertiary care hospital. Study was conducted over duration of 1 year.

After obtaining informed and written consent, a structural proforma was fulfilled after interviewing parents. Details of epilepsy were obtained in it. The behavioural functioning of child was assessed by the parents rating of the instrument child behaviour checklist. (CBCL).

The same instrument was applied to the other children between 5 to 15 years of children who were suffering from other illnesses attending paediatric OPD.

Statistical analysis of the collected data was done by SPSS (Statistical Package for Social Service) version 11.5. Results were compared with unpaired ' $\mathrm{T}$ ' test.

Correlation between behavioural problems and type of seizures was done by using ANOVA.

\section{RESULTS}

\begin{tabular}{|c|c|c|}
\hline Age in Years & No. & Percent \\
\hline 5 to 10 & 13 & 43.30 \\
\hline 10 to 15 & 17 & 56.70 \\
\hline Total & 30 & 100.00 \\
\hline
\end{tabular}

Among the 30 epileptic children, 17 were in 10 to 15 years age group and 13 patients were in 5 to 10 years age group. The prevalence rate of epilepsy increases with rising age between 0 to 4-5 years, it was approximately 3.5 per thousand. Between 5-6 and 9-10 years it was 4.5 per thousand and between 11 and 15-16 years approximately 5 per thousand. 


\begin{tabular}{|c|c|c|}
\hline Gender & No. & Percent \\
\hline Male & 17 & 56.70 \\
\hline Female & 13 & 43.30 \\
\hline Total & 30 & 100.00 \\
\hline
\end{tabular}

Table 2. Distribution of Gender among Epilepsy Cases

In this study, more boys with epilepsy were represented than girls. Many studies find prevalence rate higher for boys. Usually the difference is minor and not statistically significant.

\begin{tabular}{|c|c|c|}
\hline Age of onset of Seizures & No. & Percent \\
\hline$<5$ & 7 & 23.30 \\
\hline$>=5$ & 23 & 76.70 \\
\hline Total & 30 & 100.00 \\
\hline Table 3. Age of Onset of Seizure \\
\hline
\end{tabular}

The onset of epilepsy occurs before the age of 20 years in $60 \%$ of patients and one third has their first seizure when in junior school.

\begin{tabular}{|c|c|c|}
\hline Duration of Disease & No. & Percent \\
\hline 6 m to 1 yr. & 12 & 40.00 \\
\hline 2 yrs. & 5 & 16.70 \\
\hline$>2$ yrs. & 13 & 43.30 \\
\hline Total & 30 & 100.00 \\
\hline $\begin{array}{c}\text { Table 4. Distribution of Duration of Disease } \\
\text { among Epilepsy Cases }\end{array}$ \\
\hline
\end{tabular}

\begin{tabular}{|c|c|c|}
\hline Type of Seizure & No. & Percent \\
\hline SPS & 4 & 13.30 \\
\hline GTS & 13 & 43.30 \\
\hline CPS & 5 & 16.70 \\
\hline SPS 2nd G & 5 & 16.70 \\
\hline Abs & 1 & 3.30 \\
\hline Gen T/C/A & 2 & 6.70 \\
\hline Total & 30 & 100.00 \\
\hline Table 5. Distribution of Type of Seizure \\
among Epilepsy Cases \\
\hline
\end{tabular}

\begin{tabular}{|c|c|c|c|c|c|c|c|}
\hline \multirow{2}{*}{$\begin{array}{c}\text { Vari- } \\
\text { ables }\end{array}$} & \multicolumn{4}{|c|}{ Cases } & \multicolumn{2}{c|}{ Control } & \multicolumn{2}{c|}{ Unpaired T - test applied } \\
\hline & Mean & SD & Mean & SD & $\begin{array}{c}\text { T- } \\
\text { value }\end{array}$ & P-value & $\begin{array}{c}\text { Difference } \\
\text { is- }\end{array}$ \\
\hline CBCL-W & 0.87 & 1.96 & 0.73 & 1.76 & 0.227 & 0.783 & $\begin{array}{c}\text { Not } \\
\text { significant }\end{array}$ \\
\hline CBCL-S & 1.77 & 2.16 & 0.50 & 1.14 & 2.842 & 0.006 & Significant \\
\hline $\begin{array}{c}\text { CBCL- } \\
\text { A\&D }\end{array}$ & 2.70 & 5.23 & 1.03 & 3.70 & 1.426 & 0.159 & $\begin{array}{c}\text { Not } \\
\text { significant }\end{array}$ \\
\hline CBCL-Sp & 1.13 & 1.46 & 0.73 & 1.68 & 0.985 & 0.328 & $\begin{array}{c}\text { Not } \\
\text { significant }\end{array}$ \\
\hline CBCL-T & 0.00 & 0.00 & 0.03 & 0.18 & -1.000 & 0.321 & $\begin{array}{c}\text { Not } \\
\text { significant }\end{array}$ \\
\hline CBCL-A & 2.53 & 5.85 & 0.07 & 0.25 & 2.306 & 0.025 & Significant \\
\hline CBCL-D & 0.80 & 1.54 & 0.67 & 1.63 & 0.326 & 0.746 & $\begin{array}{c}\text { Not } \\
\text { significant }\end{array}$ \\
\hline CBCL-Agg & 4.00 & 6.11 & 1.57 & 4.02 & 1.822 & 0.074 & $\begin{array}{c}\text { Not } \\
\text { significant }\end{array}$ \\
\hline CBCL-0 & 1.13 & 1.74 & 0.40 & 1.13 & 1.937 & 0.058 & $\begin{array}{c}\text { Not } \\
\text { significant }\end{array}$ \\
\hline CBCL-Int & 4.83 & 7.58 & 2.27 & 5.13 & 1.536 & 0.130 & $\begin{array}{c}\text { Not } \\
\text { significant }\end{array}$ \\
\hline CBCL-Ext & 4.80 & 7.13 & 2.31 & 5.07 & 1.541 & 0.129 & $\begin{array}{c}\text { Not } \\
\text { significant }\end{array}$ \\
\hline CBCL- & 14.87 & 12.26 & 6.53 & 8.60 & 3.048 & 0.003 & Significant \\
\hline
\end{tabular}

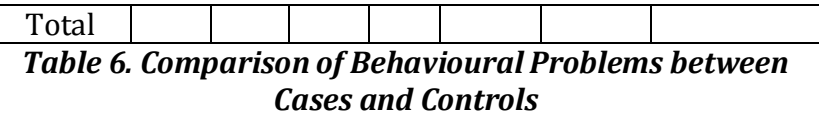

\begin{tabular}{|c|c|c|c|c|}
\hline Variables & $\begin{array}{c}\text { Mann- } \\
\text { Whitney U }\end{array}$ & $\mathbf{Z}$ & P-value & Significant \\
\hline CBCL-W & 444.500 & -0.116 & 0.907 & Not significant \\
\hline CBCL-S & 309.500 & -2.479 & 0.013 & Significant \\
\hline CBCL-A\&D & 375.500 & -1.632 & 0.103 & Not significant \\
\hline CBCL-Sp & 358.000 & -1.681 & 0.093 & Not significant \\
\hline CBCL-T & 435.000 & -1.000 & 0.317 & Not significant \\
\hline CBCL-A & 352.000 & -2.232 & 0.026 & Significant \\
\hline CBCL-D & 413.000 & -0.760 & 0.447 & Not significant \\
\hline CBCL-Agg & 342.500 & -1.160 & 0.246 & Not Significant \\
\hline CBCL-O & 355.000 & -1.896 & 0.058 & Not significant \\
\hline CBCL-Int & 349.000 & -1.687 & 0.092 & Not significant \\
\hline CBCL-Ext & 370.000 & -1.151 & 0.250 & Not significant \\
\hline CBCL-Total & 248.500 & -3.004 & 0.003 & Significant \\
\hline
\end{tabular}

In this study, higher rates of total behavioural problems were found in epileptic children as compared to those of healthy controls. This finding is consistent with study done by Hoare et al. Among the behavioural problems, statistically significant difference was found for aggression, attention and somatic problems. The difference was also clinically significant for anxiety and depression though not statistically significant.

\begin{tabular}{|c|c|c|c|c|c|c|c|}
\hline \multirow[b]{2}{*}{$\begin{array}{l}\text { Vari- } \\
\text { ables }\end{array}$} & & \multicolumn{6}{|c|}{ Type of Seizure } \\
\hline & & SPS & GTS & CPS & \begin{tabular}{|c|} 
SPS \\
$2 \mathrm{n}$
\end{tabular} & Abs & GenT/ \\
\hline \multirow{2}{*}{ CBCL-W } & Mean & 0.75 & 1.46 & 0.00 & 0.80 & 0.00 & 0.00 \\
\hline & SD & 1.50 & 2.60 & 0.00 & 1.79 & & 0.00 \\
\hline \multirow{2}{*}{ CBCL-S } & Mean & 0.50 & 1.69 & 1.40 & 3.00 & 0.00 & 3.50 \\
\hline & SD & 1.00 & 2.46 & 1.95 & 2.24 & & 0.71 \\
\hline \multirow{2}{*}{$\begin{array}{c}\text { CBCL- } \\
\text { A\&D }\end{array}$} & Mean & 0.75 & 2.23 & 0.00 & 7.60 & 0.00 & 5.50 \\
\hline & SD & 1.50 & 4.29 & 0.00 & 8.76 & & 7.78 \\
\hline \multirow{2}{*}{ CBCL-Sp } & Mean & 1.00 & 1.46 & 0.60 & 1.60 & 0.00 & 0.00 \\
\hline & SD & 1.16 & 1.61 & 1.34 & 1.67 & & 0.00 \\
\hline \multirow{2}{*}{ CBCL-T } & Mean & 0.00 & 0.00 & 0.00 & 0.00 & 0.00 & 0.00 \\
\hline & SD & 0.00 & 0.00 & 0.00 & 0.00 & & 0.00 \\
\hline \multirow{2}{*}{ CBCL-A } & Mean & 0.00 & 3.38 & 2.40 & 0.40 & 0.00 & 9.00 \\
\hline & SD & 0.00 & 6.86 & 5.37 & 0.89 & & 12.73 \\
\hline \multirow{2}{*}{ CBCL-D } & Mean & 1.00 & 0.46 & 1.20 & 1.20 & 0.00 & 1.00 \\
\hline & SD & 1.16 & 1.20 & 1.79 & 2.68 & & 1.41 \\
\hline \multirow{2}{*}{$\begin{array}{c}\text { CBCL- } \\
\text { Agg }\end{array}$} & Mean & 9.50 & 2.69 & 4.00 & 4.60 & 0.00 & 2.00 \\
\hline & SD & 7.55 & 5.22 & 7.87 & 6.31 & & 2.83 \\
\hline \multirow{2}{*}{ CBCL-O } & Mean & 1.50 & 1.00 & 0.60 & 2.40 & 0.00 & 0.00 \\
\hline & SD & 1.73 & 1.63 & 1.34 & 2.51 & & 0.00 \\
\hline \multirow{2}{*}{ CBCL-Int } & Mean & 1.25 & 4.62 & 1.40 & 10.60 & 0.00 & 10.00 \\
\hline & \begin{tabular}{|c|} 
SD \\
\end{tabular} & 2.50 & 7.67 & 1.95 & 11.44 & 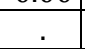 & 7.07 \\
\hline \multirow{2}{*}{ CBCL-Ext } & Mean & 10.50 & 3.15 & 5.20 & 5.80 & 0.00 & 3.00 \\
\hline & SD & 7.55 & 6.08 & 9.55 & 8.32 & & 4.24 \\
\hline \multirow{2}{*}{$\begin{array}{l}\text { CBCL- } \\
\text { Total }\end{array}$} & Mean & 15.00 & 14.23 & 10.20 & 21.60 & 0.00 & 21.00 \\
\hline & SD & 12.94 & 12.26 & 14.99 & 10.55 &. & 8.49 \\
\hline
\end{tabular}

\begin{tabular}{|c|c|c|c|}
\hline \multirow{2}{*}{ Variables } & \multicolumn{3}{|c|}{ ANOVA applied } \\
\cline { 2 - 4 } & F-value & P-value & $\begin{array}{c}\text { Difference } \\
\text { is- }\end{array}$ \\
\hline CBCL-W & 0.509 & 0.767 & $\begin{array}{c}\text { Not } \\
\text { significant }\end{array}$ \\
\hline CBCL-S & 1.029 & 0.423 & $\begin{array}{c}\text { Not } \\
\text { significant }\end{array}$ \\
\hline CBCL-A\&D & 1.594 & 0.200 & Not \\
\hline
\end{tabular}




\begin{tabular}{|c|c|c|c|}
\hline CBCL-Sp & 0.701 & 0.628 & $\begin{array}{c}\text { significant } \\
\text { Not } \\
\text { significant }\end{array}$ \\
\hline CBCL-T & 0.840 & 0.534 & $\begin{array}{c}\text { Not } \\
\text { significant }\end{array}$ \\
\hline CBCL-A & 0.294 & 0.912 & $\begin{array}{c}\text { Not } \\
\text { significant }\end{array}$ \\
\hline CBCL-Agg & 0.889 & 0.504 & $\begin{array}{c}\text { Not } \\
\text { significant }\end{array}$ \\
\hline CBCL-O & 0.920 & 0.485 & $\begin{array}{c}\text { Not } \\
\text { significant }\end{array}$ \\
\hline CBCL-Int & 1.295 & 0.299 & $\begin{array}{c}\text { Not } \\
\text { significant }\end{array}$ \\
\hline CBCL-Ext & 0.755 & 0.591 & $\begin{array}{c}\text { Not } \\
\text { significant }\end{array}$ \\
\hline CBCL-Total & 0.822 & 0.546 & $\begin{array}{c}\text { Not } \\
\text { significant }\end{array}$ \\
\hline
\end{tabular}

In this study, correlation between behavioural problems and type of seizures was not statistically significant.

\section{DISCUSSION}

The modern view of epilepsy and mental illness suggests that people with epilepsy are normal mentally but it is the brain damage and site of the lesion which leads to an association between epilepsy and mental illness.

The impact and burden of psychiatric morbidity contributes significantly to overall disability.

Ounstead (1955) found that $8 \%$ of the children with epilepsy in his clinic had inattention, overactivity, distractibility, aggression and mood lability. ${ }^{6}$

Henzburg et al in his study found an association between presence of anterior temporal lobe epileptic spikes and increased aggression score on the CBCL. ${ }^{7}$

Lewis has suggested that psychomotor epilepsy was found to be persistently associated with violence. 8

Higher rates of attention problems have been seriously reported in children with epilepsy. Semrud-Clikeman and Wical found attention problem in children with complex partial seizures. Williams and colleagues found children with epilepsy have subtle attention difficulties. ${ }^{9}$

Carlton and co-workers described impulsivity in 39\% of the children with current or past seizures and $11 \%$ of children with no history of seizures. ${ }^{10}$

McDermott and colleagues found hyperactivity in $28 \%$ of the children with epilepsy as compared to $5 \%$ in the control population. ${ }^{2}$

In the Bombay Hospital study, the incidence of behavioural problems was $34.62 \%$ as compared to $17.95 \%$ in the controls. The common behavioural problems encountered in this study were conduct disorder which were the commonest followed by vegetative disorders. Spectrum of behavioural problem seen was hyperkinesia and aggression.

Ettinger et al reported that $26 \%$ of $44 \%$ epileptic patients aged 7 to 18 yrs. had significant depression scores and $16 \%$ met criteria for anxiety symptomatology. 11

Focal EEG abnormality and complex partial seizures have been associated with increased psychiatric disturbances. Children with both epilepsy and structural CNS abnormality are more likely than not to have psychopathology, Though Dunn and Austin JK found more children with generalised seizures had symptoms of ADHD compared with partial or absence seizure. Hempel and co-workers also noted the same. Whitman et al (1982) too reported no association between temporal lobe epilepsy and psychopathology in epileptic children. ${ }^{12}$

In our study, different types of seizures were represented, less in number, and that is why findings may not be significant.

\section{CONCLUSION}

Children with epilepsy were at increased risk of behavioural problems as compared to normal healthy controls. Amongst the spectrum of behavioural problems, attention, hyperactivity, somatic and aggression problems were more. Anxiety and depression scores were clinically more in epileptic cases than controls, though no statistical significance was found. Focal EEG abnormality and complex partial seizures have been associated with increased psychiatric disturbances. In the present study, representation of different types of epilepsy was less, hence findings may not be significant.

\section{REFERENCES}

[1] Fencolck P. Epilepsy and psychiatric disorders in epilepsy. London: Chapmen and Hall 1987;11:552.

[2] McDermott S, Mani S, Krishnawami S. A population based analysis of special behavioural problems associated with childhood seizures. J Epilepsy 1995;8(2):110-8.

[3] Dunn DW, Austin JK, Huster GA. Behavior problems in children with new onset epilepsy. Seizure 1997;6(4):283-7.

[4] Hoare P. The development of psychiatric disorder among schoolchildren with epilepsy. Dev Med Child Neursol 1984;26(1):3-13.

[5] Commission on Classification and Terminology of the International League Against Epilepsy. Proposal for revised classification of epilepsies and epileptic syndromes. Epilepsia 1989;30(4):389-99.

[6] Ounsted C. The hyperkinetic syndrome in epileptic children. Lancet 1955;269(6885):303-11.

[7] Herzberg JL, Fenwick PB. The etiology of aggression in temporal-lobe epilepsy. British Journal of Psychiatry 1988;153(1):50-5.

[8] Lewis DO, Pincus JH, Shanok SS, et al. Psychomotor epilepsy and violence in group of incarcerated adolescent boys. American Journal of Psychiatry 1982;139(7):882-7.

[9] Semrud-Clikemen M, Wical B. Components of attention in children with complex partial seizures with and without ADHD. Epilepsia 1999;40(2):211-5.

[10] Carlton-Ford S, Miller R, Brown M, et al. Epilepsy and children's social and psychological adjustment. J Health Soc Behav 1995;36(3):285-301.

[11] Ettnger AB, Weisbrot DM, Nolan EE, et al. Symptoms of depression and anxiety in paediatric epilepsy patients. Epilepsia 1998;39(6):595-9.

[12] Whitman S, Hermann BP, Black RB, et al. Psychopathology and seizure type in children with epilepsy. Psychol Med 1982;12(4):843-53. 